\title{
O cuidado de enfermagem como prática empreendedora: oportunidades e possibilidades*
}

\author{
Nursing care as an enterprising social practice: opportunities and possibilities \\ El cuidado de enfermería como práctica emprendedora: oportunidades y posibilidades
}

Dirce Stein Backes ${ }^{1}$, Alacoque Lorenzini Erdmann², Andreas Büscher ${ }^{3}$

\begin{abstract}
RESUMO
Objetivos: Compreender o significado do cuidado de enfermagem como prática social empreendedora. Métodos: Foi baseada na Grounded Theory que, de forma sistemática, criativa e interativa possibilitou o desenvolvimento da teoria: "Vislumbrando o cuidado de enfermagem como prática social empreendedora". Amostra teórica constituiu-se de 35 sujeitos entrevistados, distribuídos em diferentes grupos amostrais. Resultados: O cuidado de enfermagem como prática social empreendedora está associado ao sistema de relações e interações, à capacidade de interagir com os diferentes atores sociais, na capacidade de criar novos canais de comunicação e ações pró-ativas. Conclusão: A partir do cuidado como prática social empreendedora é possível atuar de forma pró-ativa, inovadora e participativa, sem desconsiderar as contradições sociais emergentes.

Descritores: Gestão em saúde; Cuidados de enfermagem; Papel do profissional de enfermagem; Responsabilidade social; Pesquisa em enfermagem
\end{abstract}

\begin{abstract}
Objective: To understand the meaning and to develop a substantive theory about nursing care as an enterprising social practice. The Methods: Was based on the Grounded Theory which, in a systematic, creative and interactive manner allowed the development of the substantive theory: "Realizing the nursing care as an enterprising social practice." The theoretical sample consisted of thirty-five subjects distributed among different groups of samples. Results: The nursing care as an enterprising social practice is associated with the system of relationships and interactions, the ability to interact with different social actors and, the ability to create new channels of communication and proactive actions. Conclusion: Considering the care as an enterprising practice is possible to act in a proactive, innovative and participatory way, without neglecting the emerging aspects of social contradictions.
\end{abstract}

Keywords: Health management; Nursing care; Nurse's role; Social responsibility; Nursing research

\section{RESUMEN}

Objetivo: Comprender el significado y desarrollar una teoría sustantiva sobre el cuidado de enfermería como una práctica social emprendedora. Metodos: Se basó en la Grounded Theory que, como un proceso sistemático, creativo e interactivo permitió el desarrollo de la teoría sustantiva: "Vislumbrando el cuidado de enfermería como una práctica social emprendedora". La muestra teórica estuvo constituida por treinta y cinco entrevistados distribuidos en diferentes grupos de muestras. Resultados: El cuidado de enfermería como una práctica social emprendedora se asocia con el sistema de relaciones e interacciones, con la capacidad de interactuar con diferentes actores sociales y, con la capacidad de crear nuevos canales de comunicación y de acciones proactivas. Conclusión: A partir del cuidado como una práctica emprendedora es posible actuar de manera proactiva, innovadora y participativa, sin dejar de lado las contradicciones sociales emergentes.

Descriptores: Gestión en salud ; Atención de enfermería; Rol de la enfermera; Responsabilidad social; Investigación en enfermería

\footnotetext{
* Trabalho realizado na Universidade Federal de Santa Catarina - UFSC - Florianópolis (SC), Brasil.

${ }^{1}$ Doutora em Enfermagem. Professora do Curso de Enfermagem do Centro Universitário Franciscano - UNIFRA. Membro do Grupo de Estudos e Pesquisas em Administração de Enfermagem e Saúde (GEPADES). Lider do Grupo de Estudos e Pesquisas em Empreendedorismo Social da Enfermagem e Saúde (GEPESES), Santa Maria, Rio Grande do Sul (RS), Brasil.

${ }^{2}$ Doutora em Filosofia da Enfermagem. Professora Titular da Universidade Federal de Santa Catarina - UFSC. Coordenadora do GEPADES. Coordenadora da Área da Enfermagem na Coordenação de Aperfeiçoamento de Pessoal de Nivel Superior (CAPES), Florianópolis, Rio Grande do Sul (RS), Brasil.

${ }^{3}$ Doutor em Enfermagem. Professor e Pesquisador da Universität Bielefeld - Alemanha.
} 


\section{INTRODUÇÃO}

A complexidade dos problemas sociais tem induzido e mobilizado a ciência, as instituições e profissionais a buscarem estratégias criativas e inovadoras capazes de recuperar a vida e garantir a dignidade humana. Surge, nessa perspectiva, em meados da década de 90 do século $\mathrm{XX}$, um importante mecanismo de mobilização e transformação da sociedade, que se convencionou chamar empreendedorismo. $\mathrm{Na}$ origem francesa entreprende, que significa o intermediário, aquele que está no meio ou no centro e no inglês entrepreneurship, que indica posição, grau, relação, estado, qualidade, habilidade, entre outros ${ }^{(1-2)}$.

É preciso assinalar, que existe uma diferença entre o empreendedorismo de negócio ou privado, atrelado às atividades de negócio, e o empreendedorismo social, mesmo que o último tenha sido fortemente influenciado pelo primeiro. Enquanto para o primeiro, a geração de riquezas é uma maneira de mensurar a geração de valor, para o segundo, a missão social é central e concebe a riqueza como meio para alcançar determinado fim ${ }^{(3-4)}$.

O empreendedorismo social surgiu como um processo alternativo dinâmico e estratégico, dotado de mecanismos mutáveis capazes de tornar sustentáveis os produtos, serviços, organizações e, principalmente, a gestão de pessoas ${ }^{(4)}$. Para tanto, combina a paixão por uma missão social com a imagem de disciplina, inovação e determinação, alicerçadas nos valores da cidadania, além de "assumir uma atitude de inconformismo e crítica face às injustiças sociais existentes"(5). O empreendedorismo social, sob esse enfoque, faz emergir propostas práticas de resolução dos problemas sociais, criando estratégias de inserção social, projetos sociais inovadores e ações empreendedoras auto-sustentáveis.

O conceito de empreendedorismo social passou a socializar-se, mais especificamente na última década, como uma tendência organizacional e relacional capaz de expandir redes/sistemas/arranjos de compromisso social, como alternativa para abordar questões sociais complexas e aparentemente inatingíveis quando tratadas isoladamente ${ }^{(6-8)}$.

Para os autores de referência internacional, o empreendedorismo social é um paradigma emergente de um novo modelo de desenvolvimento em redes e parcerias, com foco na dimensão humana e social. Pode ser entendido, também, como um fator indutor e gerador de auto-organização do sistema social, que contribui para o desenvolvimento integrado e sustentável, bem como no enfrentamento das expressões da questão social. Nesse sentido, o empreendedorismo social gera transformação social, emancipação social e empoderamento dos cidadãos, contribuindo para a sustentabilidade e justiça social ${ }^{(9)}$.

No campo da enfermagem, as discussões sobre o empreendedorismo social são ainda bastante incipientes, tanto nacional como internacionalmente. Alguns estudos de âmbito internacional evidenciaram que vários enfermeiros buscaram novas alternativas de trabalho para se libertarem da burocracia e limites impostos pelas instituições tradicionais de cuidados em saúde. Para exemplificar, menciona-se a Clínica Norte-americana Clinical Nurse Specialist Entrepreneurship - que optou por sair do espaço hospitalar para criar o seu próprio negócio e, dessa forma, valorizar o potencial inovador e desenvolver o seu ideal com independência e autonomia ${ }^{(10)}$.

A enfermagem tem várias razões e oportunidades para ter o seu próprio empreendimento. Primeiro, por ser uma profissão que tem uma compreensão ampla da realidade, isto é, uma compreensão das necessidades do ser humano como um todo. Segundo, porque a enfermagem tem potencial e oportunidades para explorar novos campos sociais, não necessitando submeter-se aos espaços tradicionais de cuidados onde, na maioria dos casos, prevalece a noção de doença ${ }^{(11-13)}$.

Percebemos, desse modo, que iniciativas associadas ao empreendedorismo da enfermagem já são uma realidade, mesmo que o enfoque ainda esteja relacionado à compreensão de negócio. Uma das razões para isso é que o "empreendedorismo social tem recebido pouca atenção", e as iniciativas de âmbito social não provocam um impacto imediato ${ }^{(2)}$.

No campo do empreendedorismo ainda há muito a ser discutido, principalmente ao associá-lo à prática social do cuidado em enfermagem/saúde. É preciso que se multipliquem as iniciativas e que haja o suporte ao cuidado empreendedor da enfermagem, o qual gera, ainda, muitas controvérsias e dúvidas, a começar pelo debate do tema e a construção de referenciais específicos para a área. Com base no exposto, questionamo-nos enquanto profissionais do cuidado em saúde: Qual o significado do cuidado de enfermagem como prática social empreendedora? Qual o significado do cuidado empreendedor da enfermagem?

\section{OBJETIVO}

Compreender o significado do cuidado de enfermagem como prática social empreendedora.

\section{MÉTODOS}

Dentre as metodologias qualitativas, a opção para este estudo foi a Grounded Theory ${ }^{(14-15)}$ ou também chamada Teoria Fundamentada nos Dados (TFD), com o propósito de compreender o significado dos fenômenos a partir dos dados e da ação.

Trata-se de uma metodologia originalmente desenvolvida por Glaser e Strauss, sociólogos americanos que intentaram construir uma teoria assentada nos dados, 
a partir da exploração do fenômeno na realidade em que o mesmo se insere, sendo que a construção teórica explica a ação no contexto social ${ }^{(14-15)}$.

A Grounded Theory é um método de investigação qualitativa e indutiva que visa gerar novos conhecimentos a partir dos dados investigados, analisados e comparados, de maneira sistemática e concomitante. O conhecimento é construído com base na interação social e na compreensão da atividade e da ação humana nos diferentes espaços ${ }^{(15)}$.

A coleta de dados foi realizada por meio de entrevistas, norteadas, inicialmente, pelos seguintes questionamentos: Qual o significado do cuidado de enfermagem como prática social empreendedora? Qual o significado do cuidado empreendedor da enfermagem?

As entrevistas foram realizadas em três grupos amostrais conforme prevê o método de pesquisa. O primeiro grupo foi composto por enfermeiros, selecionados aleatoriamente. Considerou-se como critério de inclusão, enfermeiros que tivessem uma prática social empreendedora reconhecida.

O segundo grupo foi composto por profissionais da equipe multiprofissional da saúde, ou seja, por enfermeiros, médicos, nutricionistas, farmacologistas, odontólogos e sanitaristas, tendo presente às hipóteses resultantes do primeiro grupo, que apontaram para olhares divergentes e pouco esclarecedores em relação ao cuidado de enfermagem como prática social ${ }^{(16)}$.

Após a análise dos dados do segundo grupo, foi necessário formar um novo grupo, considerando que a saturação teórica ainda não havia sido alcançada. A relação entre os conceitos e categorias ainda não estava suficientemente clara para integrá-los e consolidá-los em uma teoria. Desse modo, o terceiro grupo foi impulsionado pelo desejo de integrar e conhecer um Projeto Social Empreendedor, localizado em uma das Favelas da Grande Florianópolis, SC, Brasil. Considerouse importante compreender as percepções destes diferentes atores quanto a sua integração num projeto social e, ainda, compreender o significado que estes mesmos atores atribuem ao cuidado de enfermagem como prática social empreendedora.

Para a amostragem teórica, procurou-se coletar dados que pudessem subsidiar a construção teórica, de forma que, ao coletar, codificar e analisar os dados, processo este que ocorreu simultaneamente, se alcançasse à saturação teórica, que foi atingida com trinta e cinco entrevistas, realizadas no período de maio a dezembro de 2007.

A cada entrevista, os dados foram transcritos e realizada uma revisão minuciosa do texto. $\mathrm{Na}$ seqüência, deu-se início à identificação das unidades conceituais. Os dados foram codificados linha por linha, comparados entre si e designados em categorias. $\mathrm{Na}$ etapa seguinte, as pesquisadoras escolheram uma categoria da codificação aberta - primeira etapa da codificação - e a colocaram como tema central, comparando-a com as demais categorias. $\mathrm{Na}$ fase a seguir, também chamada de codificação axial, os dados foram agrupados em novas formas, buscando expandir e compactar a teoria emergente a partir das conexões teóricas. Buscou-se, nessa fase, realizar o desvelamento teórico do cuidado de enfermagem como prática social, a partir do contexto causal, das interveniências, das conseqüências e das estratégias, procurando captar, ao máximo, as relações e interações subjacentes aos dados ${ }^{(16)}$.

A partir da integração dos elementos com base no modelo de paradigma e tendo realizado as conexões teóricas entre as subcategorias e categorias, foi possível caminhar em direção à codificação seletiva, terceira fase da análise, que deu origem a teoria "Vislumbrando o cuidado de enfermagem como prática social empreendedora".

Os aspetos éticos foram todos considerados. Todos os integrantes da pesquisa, após esclarecidos quanto os objetivos e metodologia do trabalho, assinaram o Termo de Consentimento Livre e Esclarecido. Os entrevistados foram caracterizados por codinomes que representam a sua principal característica empreendedora. O projeto foi aprovado pelo Comitê de Ética em Pesquisa da UFSC, sob o número $052 / 07$.

\section{RESULTADOS}

A teoria "Vislumbrando o cuidado de enfermagem como prática social empreendedora" teve como condição causal a categoria "Confrontando-se com as contradições sociais emergentes", como contexto a categoria "Reconhecendo espaços múltiplos da organização social do cuidado de enfermagem" e como condição interveniente: "As interveniências político-pedagógicas". A categoria "Necessitando ampliar a intervenção social por meio do empreendedorismo" apresentou-se como conseqüência para a categoria central "Evidenciando o cuidado de enfermagem como prática social" e a categoria "Incrementando a formação profissional do enfermeiro" como estratégia capaz de ampliar as possibilidades empreendedoras do enfermeiro por meio das práticas sociais de cuidado.

Apesar do contexto favorável que evidencia espaços múltiplos da organização social do cuidado de enfermagem, a categoria "Confrontando-se com as contradições sociais emergentes", identificada como condição causal, evidencia que o sistema, qualquer que seja ele, precisa estar atento às perturbações do entorno social. Para manter a dinâmica organizacional e os espaços de atuação profissional, a enfermagem precisa estar aberta e sensível às perturbações do entorno social para continuamente renovar os seus elementos e, 
consequentemente, possibilitar novas e sempre mais complexas comunicações de sentido.

[...] A enfermagem não tem muito esta cultura do empreendedorismo. Ela nasceu como obra de caridade e até hoje se sente isto da caridade... pela própria questão histórica dela. Ela não nasceu para o empreendedorismo, ela nasceu entre aspas para fazer o bem, e de preferência gratuitamente... A gente faz. o social, mas ainda no sentido do assistencialismo. (Motivada)

Os entrevistados, de modo geral, evidenciaram que o enfermeiro necessita maior inserção no entorno social e participação mais ativa e efetiva no desenvolvimento de projetos políticos que expressem o compromisso face às contradições da sociedade atual. Confrontar-se com as contradições sociais emergentes, faz referência à necessidade de "entrar na realidade e indignar-se", isto é, à necessidade de compreender e respeitar a complexidade da realidade da forma como ela se apresenta. Significa descobrir a organização específica de cada indivíduo e comunidade, potencializá-la e apoiar-se nela para promover as práticas de saúde.

Como condições facilitadoras do processo de ampliação e fortalecimento das ações/estratégias no desenvolvimento do cuidado de enfermagem como prática social empreendedora, foram evidenciadas as interveniências político-pedagógicas, mais especificamente as relacionadas com os princípios do SUS, às novas diretrizes para a formação acadêmica e para o avanço científico, tecnológico e de inovação da enfermagem. Para os entrevistados, "[...] existe um espaço infinito de empreendedorismo para a enfermagem", no entanto, pouco explorado.

A enfermagem tem um campo de atuação muito grande e complexo. O enfermeiro pode atuar num campo mais cientifico, mais técnico e nas questões mais amplas de consciência. O enfermeiro tem um potencial muito grande, muito amplo. É uma profissão que está sendo valorizada. Mas é o enfermeiro que precisa se valorizar. $O$ enfermeiro precisa aprender a se valorizar. Eu acredito que a enfermagem tem um potencial, tem um campo muito amplo de atuação, no campo político, social, econômico, na educação, na assistência, na bumanização (Inserida).

As interveniências político-pedagógicas se apresentam como condições facilitadoras, à medida que sinalizam para uma nova abordagem de intervenção social, não mais focada nos reducionismos do saber biomédico, mas centradas em ações próativas e inovadoras. Ou seja, à medida que, para superar o enfoque reducionista, buscam adotar perspectivas integradoras de variáveis múltiplas, para captar amplamente a complexidade do processo saúde-doença. Ou ainda, à medida que primam pelas metodologias ativas e problematizadoras, voltadas para a inserção concreta ou no contexto real do usuário, família e comunidade.

A categoria "Incrementando a formação profissional do enfermeiro", potencializada pelas interveniências político-pedagógicas, foi evidenciada como estratégia capaz de ampliar as possibilidades empreendedoras do cuidado de enfermagem como prática social. Para os entrevistados de modo geral, é preciso que a enfermagem invista, gradativamente, no desenvolvimento de uma cultura profissional voltada para o empreendedorismo social. Para muitos, a história da enfermagem esteve, ao longo dos anos, centrada na produção ou desenvolvimento de práticas "assistencialistas", centradas no "fazer o bem gratuitamente".

Para desenvolver uma cultura empreendedora é preciso, no entender dos entrevistados, incrementar o processo de formação por meio do desenvolvimento de competências voltadas para a complexidade do contexto social concreto, o que certamente tornará, ainda mais complexa, a busca de estratégias adequadas. Nessa perspectiva, é preciso superar a idéia de formar "um bom empregado para trabalhar em..." ou a idéia de formar um "profissional redondo" ou apenas um "cumpridor de normas". $\mathrm{Na}$ lógica do empreendedorismo social, o processo de formação precisa instigar nos indivíduos uma nova concepção de mundo, de sociedade e de ser humano, a partir da ampliação das oportunidades reais. Não basta, no entender dos entrevistados, "dar o peixe" ou "promover práticas caritativas". Muito mais do que isto, é preciso "ensinar o individuo a pescar".

[...] empreender... não é dar o peixe pronto, mas ensinar a pescar. É preciso ensinar cada um a serprotagonista da sua história. Não dar o peixe, mas ajudar a crescer, a encontrarem o seu espaço, a terem a possibilidade de construírem a sua história, mas de construírem juntos... (Carismático)

A categoria "Necessitando ampliar a intervenção social por meio do empreendedorismo" resultou como conseqüência do tema central "Evidenciando o cuidado de enfermagem como prática social". Mesmo que exista um contexto favorável que evidencia espaços múltiplos na organização social do cuidado de enfermagem, e interveniências político-pedagógicas que sinalizam para uma nova abordagem de intervenção social, existe, de outro modo, a necessidade de superar as barreiras culturais e de gênero, bem como as práticas hegemônicas tradicionais de cuidado. Além dessas, é preciso que a enfermagem potencialize os recursos e competências, possibilitando a transformação social por meio das ações de saúde integradas e articuladas em redes, com a finalidade de ampliar as oportunidades interativas e atitudes pró-ativas de impacto global.

Os entrevistados, de modo geral, evidenciam que a 
cultura profissional da enfermagem esteve, ao longo dos anos, baseada em princípios assistencialistas do fazer o "bem ao próximo" e do "faz̧er o bem gratuitamente", sem, contudo, a preocupação de desenvolver uma identidade política empreendedora, de impacto social sustentável. Os entrevistados deixam clara a necessidade de transcender a idéia do "fazer o bem" ou promover programas convencionais de intervenção social. Sob um novo olhar, os entrevistados evidenciam que a enfermagem precisa estar articulada com os diferentes atores sociais e promover intervenções empreendedoras sistêmicas de longo alcance.

\section{DISCUSSÃO}

Ao discutirmos a teoria "Vislumbrando o cuidado de enfermagem como prática social empreendedora", não pretendemos afirmar que esta seja uma verdade ou a única verdade em relação ao fenômeno investigado. A teoria, qualquer que seja ela, nunca se constitui numa verdade. As teorias são sempre reconstruções de uma verdade ${ }^{(15)}$.

Vislumbrando o cuidado de enfermagem como prática social pelo olhar do empreendedorismo social

O cuidado de enfermagem como prática social empreendedora, pode ser evidenciado nos mais diferentes movimentos e espaços de atuação profissional do enfermeiro. Pode ser evidenciado nos espaços múltiplos da organização social do cuidado, na dinâmica organizacional, por meio das competências humanointerativas e competências técnico-políticas do enfermeiro, bem como no confronto com as contradições sociais emergentes.

A enfermagem possui competências múltiplas e um campo de atuação amplo e socialmente reconhecido, mas precisa ousar, no sentido de explorar as oportunidades e visualizar novos espaços, entendendo que ser empreendedor é ser capaz de explorar as oportunidades e protagonizar novos campos e práticas de atuação profissional. É ter a capacidade de imaginar, desenvolver e concretizar visões, nas quais conceitos de si, sinergia, liderança e sistema de relações/interações são elementos fundamentais ${ }^{(2,17)}$.

Os enfermeiros entrevistados reconhecem, que a área de enfermagem representa infinitas possibilidades empreendedoras, mas que não possui uma cultura empreendedora. No entanto, desenvolver uma cultura empreendedora ou uma nova cultura é resultado de um processo dinâmico e gradual, no qual se inserem posturas, valores, percepções, habilidades coletivas, entre outros elementos $^{(18)}$. Significa dizer que, mesmo que a enfermagem tenha potencialidades e possibilidades empreendedoras, o desenvolvimento de uma nova cultura torna-se fundamental para fortalecer as possibilidades interativas por meio das parcerias e redes de colaboração solidária.

Ao mencionarem a necessidade de desenvolver uma cultura empreendedora, os entrevistados evidenciam que o processo de mudança, ou o desenvolvimento de uma proativa, precisa começar pela formação, ou seja, é preciso começar instigar os graduandos que existem outras fronteiras a serem exploradas. Configurar algo novo, ou desenvolver uma nova cultura, implica em alargar as fronteiras e a visão de futuro por meio da formação de lideranças proativas, para assegurar a continuidade do processo de inovação e transformação ${ }^{(18)}$. Dito de outro modo, consiste em fazer algo por uma comunidade(2), por um grupo de pessoas, não no sentido assistencialista, mas no sentido de promover o desenvolvimento local coletivo e participativo, nesse caso, por meio das práticas de promoção da saúde.

A idéia básica do empreendedorismo social é ter um sonho e colocá-lo em prática, comprometendo o maior número possível de pessoas em torno de uma causa comum. Reforçando o que já foi dito, é imprescindível o desenvolvimento de parcerias e redes de colaboração solidária, com vistas a superar as práticas assistencialistas ou os programas convencionais, e formar um estoque de capital social, com o objetivo de mobilizar recursos de forma ativa e participativa ${ }^{(2,19)}$.

Nessa direção, é preciso crescentemente fortalecer as ações integrativas e integradoras, a fim de valorizar e potencializar o conhecimento interdisciplinar e o saber popular, ou seja, as qualidades e iniciativas dos diferentes atores sociais. É preciso dialogar com o conhecimento dos diferentes atores sociais e construir a partir das pequenas ou grandes conquistas dos indivíduos e comunidades, mesmo que isto implique em negociar com a incerteza. Significa possibilitar o sujeito ser protagonista da sua história e considerar que, quanto mais perto a decisão fica do fato, mais a decisão a ser tomada é legítima e mais chances haverá de acerto $^{(8)}$.

Promover o empreendedorismo social, implica em promover uma mudança de paradigma na forma de encarar e conduzir os problemas sociais. Significa superar as ações convencionais centradas em práticas assistencialistas, desacompanhadas de reflexão crítica e de uma participação ativa nas discussões coletivas. Significa incorporar a eficiência sistêmica em vez de eficiências individuais. Significa superar os problemas sociais através da definição coletiva de objetivos que envolvem a articulação dos diferentes atores e setores sociais ${ }^{(5)}$.

$\mathrm{Na}$ perspectiva do empreendedorismo social, o cuidado de enfermagem, como prática social, precisa estar articulado de forma a ser capaz de superar as ações convencionais e unilaterais de intervenção social, como já fora dito anteriormente. Precisa promover ações que permitam ao indivíduo ser protagonista da sua história. 
Nessa direção, a auto-organização( ${ }^{(9)}$ se mostra como importante estratégia para o desenvolvimento integrado e sustentado das ações locais, com efeito global e impacto social significativo, como mostra a Figura 1.

Para os entrevistados, é preciso mostrar o impacto do cuidado de enfermagem enquanto prática social local, articulada em redes e parcerias. As ações de impacto, por meio do cuidado de enfermagem, podem ser evidenciadas até mesmo dentro de uma estrutura organizacional, desde que o profissional tenha consciência do seu papel social. Desse modo, o cuidado de enfermagem como prática social empreendedora, precisa ser estimulado, no sentido de promover ações locais e de impacto social.

É possível argumentar, nessa direção, que a transformação social proposta pelo empreendedorismo social surge, naturalmente, das relações e interações sistêmicas, onde cada sistema age localmente, num contexto em que outros também agem, tendo como resultado a auto-organização social, isto é, o desenvolvimento social de forma ampla e integradora ${ }^{(2,9)}$. Para tanto, é preciso, valorizar as iniciativas pela integração do diferente.

Para os entrevistados, a enfermagem precisa ir além dos limites institucionalizados, ou seja, precisa ir ao encontro dos indivíduos e comunidades e inserir-se de forma concreta nos questões sociais emergentes. Os enfermeiros precisam compreender a problemática local, além da necessidade de inserirem-se ativamente nas políticas públicas voltadas para a superação dos problemas locais.
Nesse sentido, o empreendedorismo social da enfermagem está relacionado à capacidade do sistema continuamente se auto-organizar e auto-recriar, por meio de processos interativos facilitados e potencializados pela diferenciação e interdependência com o entorno social, isto é, com os diferentes setores e atores sociais.

A teoria "Vislumbrando o cuidado de enfermagem como prática social empreendedora" evidencia, em suma, que o cuidado de enfermagem por meio de ações empreendedoras articuladas em rede e parcerias, pode gerar transformação social, empoderamento dos usuários por meio das práticas de educação e promoção da saúde e, ainda, aumentar o estoque social, de forma a contribuir para o desenvolvimento e justiça social.

\section{CONCLUSÃO}

Cientes das fortes influências do paradigma convencional disjuntivo nas ciências e na realidade social como um todo, é possível argumentar que o empreendedorismo social se constitui num importante mecanismo de intervenção social, pela integração de uma visão sistêmica, intermediado pela multiplicidade de relações, interações e associações. Em outras palavras, pela possibilidade de promover o desenvolvimento social, a partir da ampliação das oportunidades reais dos seres humanos se desenvolverem como protagonistas da sua história.

O empreendedorismo social, diferentemente do que muitos pensam ou imaginam, não depende unicamente

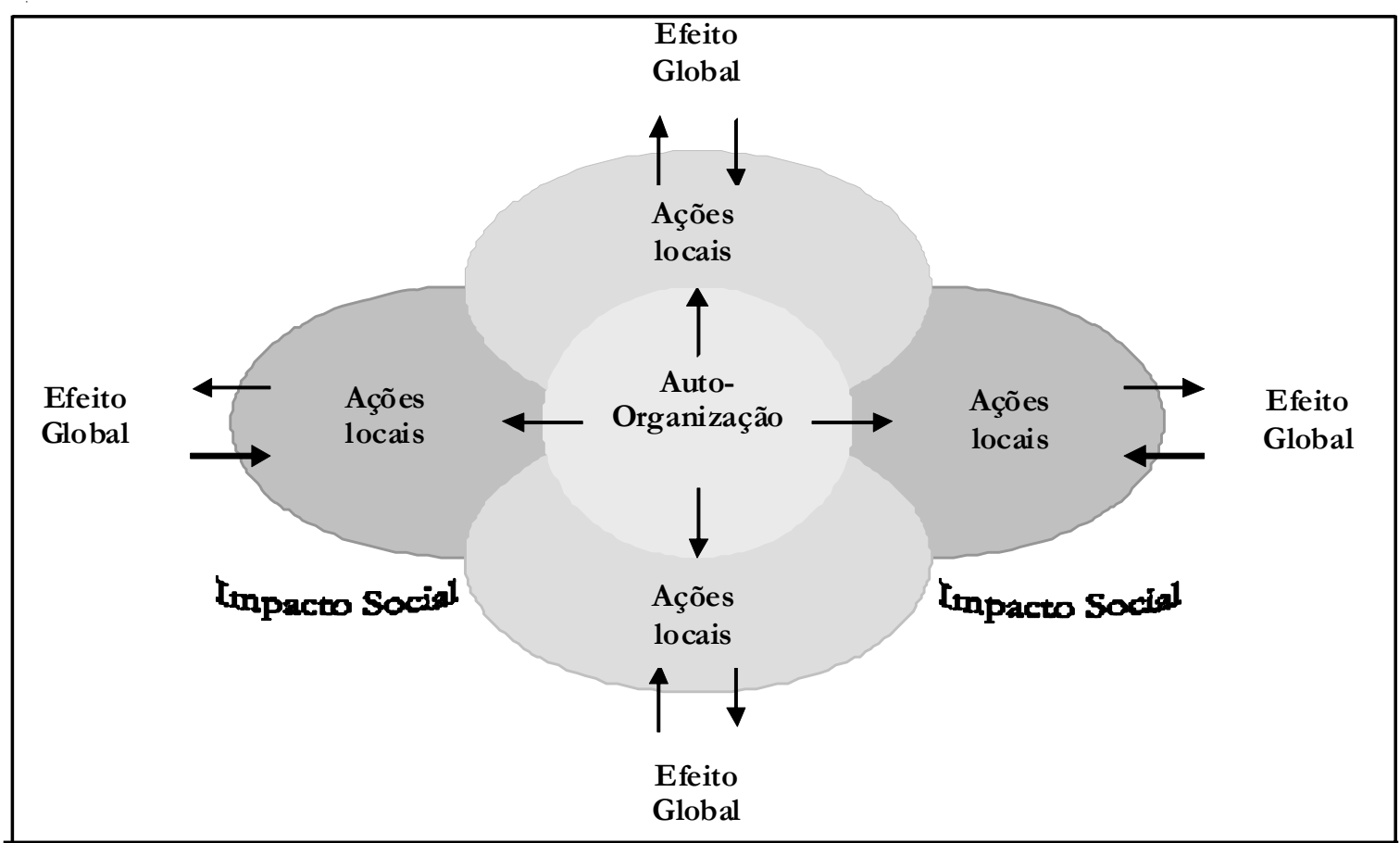

Fonte: Quadro elaborado a partir das reflexões teóricas da auto-organizaçãoOliveira EM. Empreendedorismo social no Brasil: fundamentos e estratégias [tese]. Franca (SP): Faculdade de História, Direito e Serviço Social da Universidade Estadual Paulista; $2004^{(9)}$.

Figura 1: A auto-organização como estratégia para o cuidado empreendedor 
de fatores econômicos ou financeiros. Depende, sobretudo, de ações integradas e integradoras, potencializadas pelas organizações-rede, ou seja, por meio das ações influenciadas pelos diferentes sistemas que, no conjunto, provocam efeitos globais e de impacto social.

A teoria substantiva "Vislumbrando o cuidado de enfermagem como prática social empreendedora" levanos a compreender e sintetizar que, no cenário atual, o sistema de enfermagem possui uma função essencial e altamente diferenciada, à medida que a sua comunicação socialmente relevante é o bem-estar do ser humano como um todo. Basta, no entanto, que a enfermagem invista em atitudes pró-ativas, capazes de promover o desenvolvimento social pela ampliação das oportunidades reais dos seres humanos desenvolverem suas potencialidades e, dessa forma, torná-los sujeitos do seu processo saúde-doença.

Falar em atitudes sociais pró-ativas baseadas na educação e promoção da saúde, implica falar em atitudes empreendedoras de intervenção social que, por sua vez, induzem o desenvolvimento de um saber complexo, capaz de levar em conta as variáveis múltiplas do processo saúde-doença. Considerar as variáveis múltiplas do processo saúde-doença significa considerar o caráter

\section{REFERÊNCIAS}

1. Drucker PF. Inovação e espírito empreendedor: práticas e princípios. 4a ed. São Paulo: Pioneira; 1994.

2. Bornstein D. How to change the world: social entrepreneurs and the power of new ideas. Oxford: University Press; 2007.

3. Pereira HJ. Criando o seu próprio negócio: como desenvolver o potencial empreendedor. Brasília: SEBRAE; 1995.

4. Dees JG. O significado do "Empreendedorismo social" Internet]. 2001. [citado 2001 Mai 30] Disponível em: http:/ /aprendiz.uol.com.br/downloads/educacao_comunitaria/ significado.pdf.

5. Melo Neto FP, Froes C. Empreendedorismo social: a transição para a sociedade sustentável. Rio de Janeiro: Qualitymark; 2002.

6. Dantas M. Capitalismo na era das redes: trabalho, informação e valor no ciclo da comunicação produtiva. In: Lastre HMM, Albagli S, organizadoras. Informação e globalização na era do conhecimento. Rio de Janeiro: Campus; 1999. p. 57-63.

7. Dowbor L. Tecnologias do conhecimento: os desafios da educação. Rio de Janeiro: Vozes; 2001.

8. Martins PH. Ação Pública, redes e arranjos familiares. In: Fontes B, Martins PH, organizadores. Redes, práticas associativas e gestão pública. Recife: Editora Universitária da UFPE; 2006. p.19-50.

9. Oliveira EM. Empreendedorismo social no Brasil: fundamentos e estratégias [tese]. Franca (SP): Faculdade de História, Direito e Serviço Social da Universidade Estadual Paulista; 2004.

10. Dayhoff NE, Moore PS. Entrepreneurial clinical nurse interativo das redes e parcerias, cujo processo resulta na ampliação das oportunidades que, por sua vez, multiplicam as possibilidades para intervir na causa dos problemas sociais emergentes.

Diante dos apelos e necessidades da sociedade atual, fazer apenas o que está posto pode ser considerado uma atitude irresponsável. É preciso empreender, no sentido de desenvolver políticas sociais centradas no processo de viver saudável dos indivíduos. Promover a diferenciação do sistema de enfermagem por meio do empreendedorimo social, significa avançar para o campo social, onde as chances de inovar, criar e estabelecer parcerias são maiores, e cujos resultados estão mais diretamente relacionados à educação e promoção da saúde.

"Vislumbrar o cuidado de enfermagem como prática social empreendedora", faz referência, em suma, à necessidade de mobilizar e integrar os diferentes sistemas funcionalmente diferenciados, numa perspectiva de rede, buscando potencializar e multiplicar as competências individuais e os recursos locais. No contexto da saúde, significa criar e mobilizar um plano integrado e individualizado de cuidados para o desenvolvimento de políticas sociais, capazes de compreender a complexidade dos fatores que envolvem o ser humano em seu contexto real e concreto.

specialists: innovators of patient care. Clin Nurse Spec. 2002;16(5):274-6.

11. Leong SL. Clinical nurse specialist entrepreneurship. Internet J Nurs Pract. 2005;7(1):123-9.

12. Menzies TV. Entrepreneurship and the Canadian Universities. Report of a National Study of Entrepreneurship Education. Ontário: Brock University Press; 2004.

13. Kemmer LF, Silva MJP. Como escolher o que não se conhece? Um estudo da imagem do enfermeiro por alunos do ensino médio. Acta Paul Enferm. 2007;20(2):125-30.

14. Strauss A, Corbin J. Bases de la investigación cualitativa: técnicas y procedimientos para desarrollar la teoría fundamentada. Medelin: Editorial Universidad de Antioquia; 2002.

15. Strauss A, Corbin J. Pesquisa qualitativa: técnicas e procedimentos para o desenvolvimento de teoria fundamentada. 2a. ed. Porto Alegre: Artmed; 2008.

16. Glaser BG, Strauss AL. The discovery of grounded theory: strategies for qualitative research. Hawthorne, N.Y.: Aldine de Gruyter; c1967.

17. Araújo MH, Lago RM, Oliveira LCA, Cabral PRM, Cheng LC, Filion LJ. O estímulo ao empreendedorismo nos cursos de química: formando químicos empreendedores. Quím Nova. 2005;28 Supl:S18-25.

18. Murad A. Gestão e espiritualidade: uma porta entreaberta. São Paulo: Paulinas; 2007.

19. Coleman JS. Foundations of Social Theory. Cambridge, Mass.: Belknap Press of Harvard University Press; 1990. 